\author{
Ayad H. Mseer \\ Civil Engineering \\ Department, University of \\ Technology, Iraq. \\ ayad mseer@yahoo.com
}

Received on: 27/06/2019

Accepted on: 20/07/2019

Published online: 25/12/219

\section{Effect of Weather Conditions on the Properties of Cement Rendering}

\begin{abstract}
The cement mortar used in rendering external walls, in Iraqi hot weather summer, suffers from appearance of many cracks on surface during and after its setting. So, this research aims to study the effect of different factors that can affect those cracks. The studied variables include mix proportions of mortar, grading of the used sand, method of curing, and environmental temperature (rendering during winter or summer). The rendering was laid on two types of walls build from clay bricks or concrete blocks. Tests were carried out on the mortar mixes of the different variables including flow test and drying shrinkage. Results indicate that the suitable flow of cement mortar for rendering should be $190 \pm 10 \%$, which means the water content should be higher than that required for standard flow of $110 \pm 5 \%$ by $10 \%$. Also, found that the amount of cement and water content and fineness of sand have an important role in the appearance of cracks on the cement rendering. Those cracks can be reduced to large extent by a continuous water spraying twice daily for seven days.
\end{abstract}

Keywords- Cement rendering, Weather conditions

How to cite this article: A.H. Mseer, "Effect of weather conditions on the properties of cement rendering", Engineering and Technology Journal, Vol. 37, Part A, No. 12, pp. 536-541, 2019.

\section{Introduction}

Cement rendering is done by applying a layer of cement mortar on the outer surface of construction. This process applied to protect the walls of the building from ambient environment and addition aesthetic view to it. It is known that ambient temperature has great role on the behavior of cement mortar during setting and hardening. This effect depends on properties and content of cement and sand used, in addition to $\mathrm{w} / \mathrm{c}$ ratio [1].

The main problem in cement rendering in Iraq is the appearance of cracks at early age or after it harden, especially in summer hot weather that reach a temperature of $50-60^{\circ} \mathrm{C}$.

The aim of this research is to study the effects of ambient temperature changes through the year, especially the hot weather, on properties of cement mortar. The cement mortar used with different mix proportions, cured by different methods, in addition to variables resulting in its properties during its applying, as a rendering layer, on clay bricks and concrete blocks walls.

\section{Materials}

\section{Cement}

Ordinary Portland cement satisfying Iraqi specification 5/1984 [2] has been used in this work. Table 1 shows its properties.

\section{Sand}

Three types of sand have been used:

S1: Graded sand with grading satisfying zone 3 of Iraqi specification 45/1984 [3] and British specification 882/1992 [4], as shown in Table (2). Its sulfate content $\left(\mathrm{SO}_{3}\right)$ is $0.39 \%$. This type used to prepare reference mixes.

S2: This type prepared by sieving sand S1 to produce grading satisfying requirement for sand used for rendering (Table 2), according to British specification 1199/1976 [5]. This type used to prepare cement rendering and samples for testing compressive strength and drying shrinkage exposed to laboratory environment.

S3: Very fine sand with grading even not satisfy zone 4 of British specification 882/1992 [4], as shown in Table 2. Its sulfate content $\left(\mathrm{SO}_{3}\right)$ is $0.32 \%$. This type used to prepare cement rendering and samples for testing compressive strength and drying shrinkage exposed to environmental conditions.

\section{Water}

Tap water used in mixing and curing.

\section{Building Units}

Two types of building units used in building walls to be rendered:

a) Clay bricks of $240 * 115 * 75 \mathrm{~mm}$ dimension.

b) Concrete blocks of $200 * 200 * 400 \mathrm{~mm}$ dimension.

\section{Preparing samples and their tests}

\section{Cement Mortar}

Different mix proportions have been used for cement mortar (Table 3). Those mixtures are tested in their fresh state according to ASTM C230-14 [6]. While in hardened state tested by 
length change according to ASTM C596 -09 [7] using $25 * 25 * 250 \mathrm{~mm}$ prism samples. The samples were cured by three methods:

C: Continuous curing in water inside the laboratory until testing age, for reference mixes.

C1: The samples were sprayed by water twice for the first day after demolding them, then left outside the laboratory until testing age.

C7: The samples were sprayed by water twice for seven days after demolding them, then left outside the laboratory until testing age.

\section{Cement Rendering}

Six walls of $180^{*} 150 \mathrm{~cm}$ have been built, three of them used clay bricks and the other three used concrete blocks in building. Sand type S1 used in the binding mortar of 1:3 mix proportion. One of the walls from each type placed in shade while the others placed to be expose to the sun. All the walls faces directed to north south.
The walls were sprayed with water before applying the rendering layer with $20 \mathrm{~mm}$ thickness. The cement rendering used with different mix proportions and two w/c ratio; (W1) to have flow of $120-130 \%$ and (W2) to have flow of $190 \pm 10 \%$. Another factor studied is by choosing a cement rendering mixture to be left for one hour in the ambient environment. This mixture re-tempered by addition certain amount of water to regain its initial workability and then remixed before its application on the wall. Table 4 shows the details of cement rendering samples. After one day of applying the rendering on the walls, the demec points were fixed on it in horizontal and vertical direction at distances of 20 $\mathrm{cm}$ to measure the strain obtained. In addition, the cracks that occur in the samples were observed after placing them directly in a precise and continuous way with the naked eye and determining their width using the magnifying glass and following the changes that occur in these cracks with time.

Table 1: Chemical composition and physical properties of cement

\begin{tabular}{lllll}
\hline \hline Compound of cement & Result & Property & Result & Requirement of Iraqi specification \\
\hline $\mathrm{C}_{3} \mathrm{~S}$ & 31.05 & Fineness, $\mathrm{cm}^{2} / \mathrm{g}$ & 2838 & 2300 (min.) \\
$\mathrm{C}_{2} \mathrm{~S}$ & 37.58 & Initial setting, min. & 130 & 45 (min.) \\
$\mathrm{C}_{3} \mathrm{~A}$ & 10.18 & Final setting, min. & 210 & 600 (max.) \\
$\mathrm{C}_{4} \mathrm{AF}$ & 9.95 & Comp. strength, MPa, at age & & \\
& & 3 days & 19.5 & 15 (min.) \\
& & 7 days & 27 & 23 (min.) \\
\hline
\end{tabular}

Table 2: Sieve analysis of the used sands

\begin{tabular}{lllllll}
\hline \hline $\begin{array}{l}\text { Sieve } \\
\text { size, } \\
\text { mm }\end{array}$ & \multicolumn{2}{l}{ \% passing by weight } & S2 & $\begin{array}{l}\text { Requirements for sand used in } \\
\text { rendering works according to } \\
\text { B.S. 1199 }\end{array}$ & $\begin{array}{l}\text { S3 } \\
\text { zone 3 of B.S.882 }\end{array}$ & $\begin{array}{l}\text { Requirements for } \\
\text { zequirements for } \\
\text { zone 4 of B.S.882 }\end{array}$ \\
\hline 9.5 & 100 & 100 & 100 & 100 & 100 & 100 \\
4.75 & 98.77 & $90-100$ & 100 & 100 & 100 & $95-100$ \\
2.36 & 89.50 & $85-100$ & 100 & $90-100$ & 100 & $95-100$ \\
1.18 & 81.90 & $75-100$ & 91.5 & $70-100$ & 99.7 & $90-100$ \\
0.6 & 66.63 & $60-79$ & 74.44 & $40-80$ & 94.1 & $80-100$ \\
0.3 & 19.00 & $12-40$ & 21.22 & $5-40$ & 55.8 & $15-50$ \\
0.15 & 3.17 & $0-10$ & 3.54 & $0-10$ & 17.8 & $0-15$ \\
0.075 & ---- & ---- & --- & --- & 1.9 & --- \\
\hline
\end{tabular}

Table 3: Mix proportions for cement mortar

\begin{tabular}{lllll}
\hline \hline Type of sand & $\begin{array}{l}\text { cement: sand } \\
\text { ratio }\end{array}$ & w/c ratio & $\begin{array}{l}\text { Method } \\
\text { of curing }\end{array}$ & Notes \\
\hline S1 & $1: 2$ & $0.36,0.4,0.44,0.48$ & $\mathrm{C}, \mathrm{C} 1, \mathrm{C} 7$ & casted in winter at $10 \pm 2^{\circ} \mathrm{C}$ and $50-70 \%$ R.H. \\
S1 & $1: 3$ & $0.48,0.56,0.52,0.55$ & & \\
S1 & $1: 4$ & $0.55,0.58,0.65,0.65$ & & \\
S2 & $1: 2$ & $0.48,0.54$ & $\mathrm{C} 1, \mathrm{C} 7$ & casted in summer at $42 \pm 4{ }^{\circ} \mathrm{C}$ and $13-17 \%$ \\
S2 & $1: 3$ & $0.6,0.64$ & & R.H \\
S2 & $1: 4$ & $0.72,0.76$ & & casted in summer at $42 \pm 4^{\circ} \mathrm{C}$ and $13-17 \%$ \\
S3 & $1: 3$ & $0.7,0.75$ & $\mathrm{C} 1$ & R.H \\
& & & & \\
\hline
\end{tabular}


Table 4: Mix proportions of cement rendering

\begin{tabular}{lllll}
\hline \hline Type of the wall & cement: sand ratio & Type of sand & \multicolumn{2}{c}{ w/c ratio } \\
\cline { 3 - 5 } & & & W1 & W2 \\
\hline \multirow{4}{*}{ Clay bricks } & $1: 2$ & $\mathrm{~S} 2$ & 0.48 & 0.54 \\
& $1: 3$ & $\mathrm{~S} 2$ & 0.6 & 0.64 \\
& $1: 4$ & $\mathrm{~S} 2$ & 0.72 & 0.76 \\
Concrete blocks & $\mathrm{S} 2$ & 0.6 & --- \\
& $1: 3$ & $\mathrm{~S} 2$ & $0.6+0.02$ & --- \\
& $1: 3 *$ & $\mathrm{~S} 2$ & 0.48 & 0.54 \\
& $1: 2$ & $\mathrm{~S} 2$ & 0.6 & 0.64 \\
& $1: 4$ & $\mathrm{~S} 2$ & 0.72 & 0.76 \\
& $1: 3$ & $\mathrm{~S} 3$ & 0.7 & 0.75 \\
\hline
\end{tabular}

* Re-tempered after one hour from initial mixing

Table 5: Drying shrinkage for cement mortar samples casted at summer*

\begin{tabular}{|c|c|c|c|c|c|c|c|c|c|}
\hline \multirow[t]{4}{*}{$\begin{array}{l}\text { Mix } \\
\text { proportion }\end{array}$} & \multirow[t]{2}{*}{ w/c ratio } & \multirow[t]{2}{*}{$\begin{array}{l}\text { Curing } \\
\text { method }\end{array}$} & \multicolumn{6}{|c|}{$\begin{array}{l}\text { Drying shrinkage at age, days, micro- } \\
\text { strain }\end{array}$} & \multirow[t]{3}{*}{ Notes } \\
\hline & & & 3 & 7 & 28 & 90 & 180 & 365 & \\
\hline & \multirow[t]{2}{*}{0.48} & $\mathrm{C} 1$ & 448 & 580 & 1080 & 1150 & 1290 & 1305 & \\
\hline & & $\mathrm{C} 7$ & 400 & 470 & 940 & 1000 & 1130 & 1275 & \multirow[t]{3}{*}{ Using sand S2 } \\
\hline \multirow[t]{5}{*}{$1: 2$} & \multirow[t]{2}{*}{0.54} & $\mathrm{C} 1$ & 460 & 880 & 1098 & 1208 & 1478 & 1488 & \\
\hline & & $\mathrm{C} 7$ & 428 & 828 & 1028 & 1108 & 1258 & 1388 & \\
\hline & \multirow[t]{2}{*}{0.6} & $\mathrm{C} 1$ & 320 & 446 & 543 & 720 & 975 & 1140 & \multirow[t]{2}{*}{ Using sand S2 } \\
\hline & & $\mathrm{C} 7$ & 300 & 410 & 545 & 705 & 957 & 1130 & \\
\hline & 0.6 & $\mathrm{C} 1$ & 280 & 380 & 480 & 570 & 900 & 1110 & \multirow{2}{*}{$\begin{array}{l}\text { Using sand } \mathrm{S} 2 \text {, } \\
\text { Re-tempering after one } \\
\text { hour }\end{array}$} \\
\hline \multirow[t]{3}{*}{$1: 3$} & +0.02 & $\mathrm{C} 7$ & 210 & 350 & 420 & 570 & 870 & 1080 & \\
\hline & 0.7 & $\mathrm{C} 1$ & 360 & 600 & 1140 & 1650 & 1850 & 1920 & Using sand $\mathrm{S} 3$ \\
\hline & 0.72 & $\mathrm{C} 1$ & 180 & 270 & 550 & 330 & 640 & 760 & \\
\hline \multirow[t]{3}{*}{$1: 4$} & & $\mathrm{C} 7$ & 40 & 110 & 230 & 360 & 520 & 680 & \multirow[t]{3}{*}{ Using sand S2 } \\
\hline & \multirow[t]{2}{*}{0.76} & $\mathrm{C} 1$ & 220 & 350 & 470 & 540 & 700 & 830 & \\
\hline & & $\mathrm{C} 7$ & 60 & 370 & 270 & 370 & 590 & 730 & \\
\hline
\end{tabular}

*temperature $42 \pm 4^{\circ} \mathrm{C}$ and R.H. $13-17 \%$

\section{Results and Discussion}

\section{Workability}

It is important to have certain workability in cement mortar to be rendered in efficient form. The suitable flow of cement mortar for rendering should be $190 \pm 10 \%$ (as stated by rendering workers in this research), which means the water content should be higher than that required for standard flow of $110 \pm 5 \%$ by $10 \%$.

Different variables that affect workability of mortar have been studied. Figure 1 indicate the effect of sand: cement ratio on this property, which may change depending on the importance of the building to be rendered [8]. Results indicate that it is important to increase $\mathrm{w} / \mathrm{c}$ ratio with increasing sand content to have the same required spread of the mix. This is due to increase of water required of absorption and wetting of sand particles surface. Figure 2 shows that grading of sand has significant effect on workability, where it reduces with increase sand fineness due to increase its surface area. This effect increases with increasing sand content in the mix. To obtain the standard flow $110 \pm 5$ of mix proportions $1: 2$ and $1: 4$, the ratio of $w / c$ ratio should be increased from 0.4 to 0.64 respectively for the same used sand S2. Also, this Figure 2 shows that water content should be increased by about 20\% when using fine sand S3 compared to that for mix using S2 sand to have the same flow.

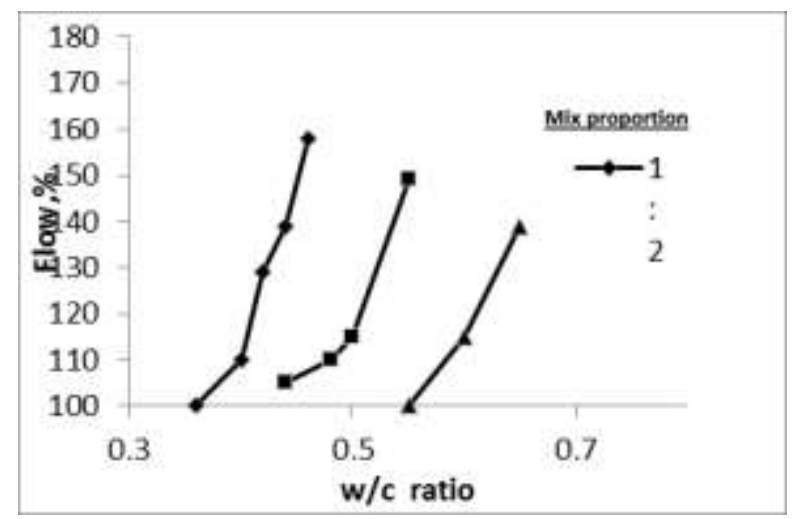

Figure 1: Flow of cement mortar, measured in the laboratory 


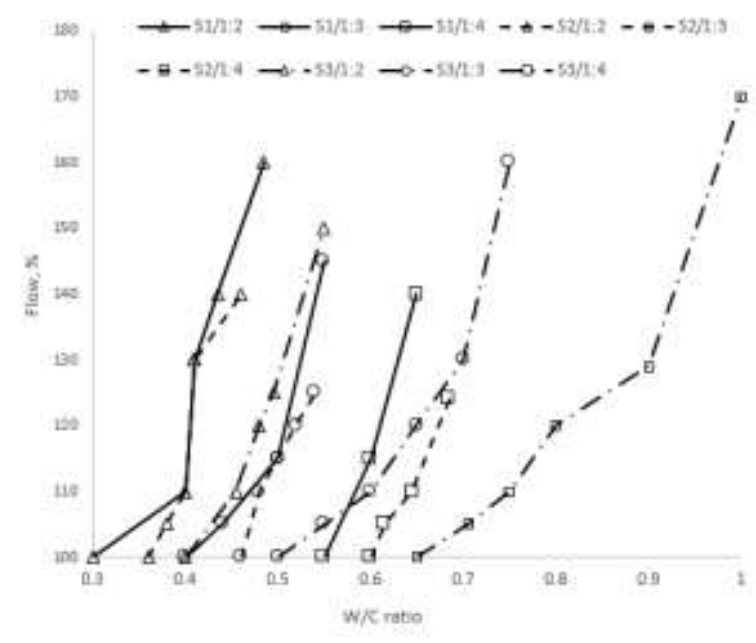

Figure 2: Effect of sand grading on flow of mortar of different mix proportions

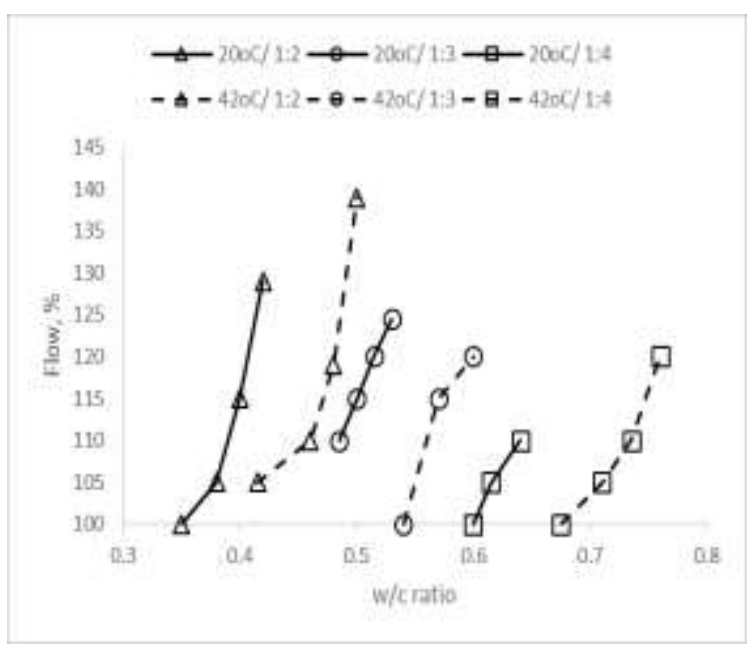

Figure 3: Effect of ambient temperature on flow of cement mortar

Figure 3 shows that the ambient temperature has significant effect on flow of cement mortar. Results indicate that the required water content, to have constant flow, need to be raised by about $15 \%$ when casting the samples outside the laboratory at $40^{\circ} \mathrm{C}$ compared to those casted inside the laboratory at $20^{\circ} \mathrm{C}$. This is due to evaporation of water from mixture and increasing heat of hydration in hot weather. The effect of retempering the cement mortar was studied for mortar with mix proportion (1:3), having a flow of $110 \pm 5$. Figure 4 shows that there is a need to add an amount of water to the mix after a period of time from mixing to regain its workability needed for rendering. This reflects practicality when leaving the mortar for a period of exposure to weather conditions prior to use.

\section{Drying Shrinkage of Cement Mortar Samples}

Studying the drying shrinkage for different mortar mixes is important because it is the main cause of the appeared cracks. Table 5 indicates that shrinkage increase with increase w/c ratio and decrease with increase sand/cement ratio. Results indicate that shrinkage for mixes 1:2 and $1: 3$, cured using method $\mathrm{C} 1$, is higher than that for mix $1: 4$ by 82 and $60 \%$ respectively. Also, grading of sand affect the shrinkage. The shrinkage of mix (with cement: sand 1:3) that uses fine sand $\mathrm{S} 3$ is higher than that for same mix with equal flow, using sand S2 by $68 \%$ at one year age. This is because fine sand have higher surface area and so need higher water content for equal flow. This lead to increase drying shrinkage of cement mortar.

Table 5 shows also that increasing curing period (curing method C7) cause reduction in drying shrinkage compared to samples cured for one day (C1). This might be due to compensation of water lost by evaporation and to give longer time for hydration of cement and reduce capillary pores in it [9]. Another factor studied is the effect of retempering on drying shrinkage of cement mortar. It can be seen that the shrinkage of re-tempered mixtures is lower than those of the same workability, curing method and type of sand used although there was a small amount of water added to the mix. This might be due to hydration of part of cement between the period from initial mixing and re-tempering (one hour).

\section{Drying Shrinkage of Cement Rendering}

The strain in cement rendering samples was measured through (Demec points) which applied on them at $200 \mathrm{~mm}$ distance. It was noticed that this strain increased with age progress and with cement content increasing (Figure 5). This behavior is the same as that noticed for ordinary mortar samples. The results show that there is a significant decrease in dry shrinkage of cement rendering when cured for 7 days (C7) compared to that cured for one day $(\mathrm{C} 1)$.

Figure 6 shows that the drying shrinkage of cement rendering when using fine sand ( $\mathrm{S} 3$ ) is more than that using coarser sand (S2). This is because of using higher w/c ratio in the mix with sand S3.

When comparing the shrinkage in cement rendering (Figure 5) with shrinkage in mortar samples. It can be noticed that the shrinkage in cement rendering is less than that in cement mortar samples. This might be due to the bond strength between the cement rendering and the walls which restrict the deformation of rendering resulting from shrinkage. This shrinkage cause stresses in cement rendering that cause cracks in it. 


\section{Cracks in the cement rendering and their spread}

After observation the appearance of cracks and their spread in the rendering mortar (applied on the walls of the bricks or blocks). They can be classified into the following:

A- Crack before setting: These cracks generally appeared during the first two hours from applying the cement rendering on the wall. They are of two types:

1- Long cracks (longer than $1 \mathrm{~mm}$ ): Accompanied by deformation of the surface of the mortar and occur on the walls made of the block with a soft surface as a result of mortar slipping and nonadhesion to the wall.

2- Small cracks $(0.2-0.75 \mathrm{~mm}$ long): Form as a result of the plastic shrinkage in the rendering mortar.

\section{B-Cracks after setting and during hardening:}

These cracks appear with time. Their length are shorter than the first type (less than $0.5 \mathrm{~mm}$ ). These cracks occur due to tensile stresses in the rendering mortar caused by shrinkage or because of the difference of thermal expansion between the mortar and the wall.

The results indicate that the cement content in the mix has main role in determining the age that cracks occur. Generally, cracks were occurred in mixes 1:2 and 1:3 at one day and 7 days age respectively. While for mix 1:4 they appeared after six months. As the age progresses, new cracks occur or the cracks become longer and begin to connect with each other. This phenomenon is increased by increasing cement content in the mixture due to increased shrinkage. It was noticed that when increasing water content in the mix, the number of cracks increase, and appear in early age. This is due to increase in drying shrinkage. When comparing the cracks appeared in the rendering applied on the brick and block walls and their relation with water content in the mortar, it is noticed that the cracks on the block walls are more than those on brick walls. This might be due to the high absorption of bricks compared to the blocks which reduce the effective water content in mortar leading to reduction of shrinkage. On the other hand, it was noticed that continuing curing (C7) has a noticeable effect on reduction cracks on the cement render. This was the same behavior on shrinkage that was discussed earlier. It was noticed that cement render, using fine sand S3, show cracks at earlier age (28 days). This is due to the high water content (Table 5) required from the cement rendering man to obtain the appropriate consistency, in addition to the high shrinkage of this type of mortar. On the other hand, there was no clear effect of the process of re-tempering of the mixture (1:3) after an hour of initial mixing, especially at early ages. Nevertheless, the cracks appeared after six months with a larger number compared to the usual reference mix (1:3) that show cracks at oneyear age. This might be due to decrease in mortar strength that was re-tempered, due to increase of its $w / c$ ratio.

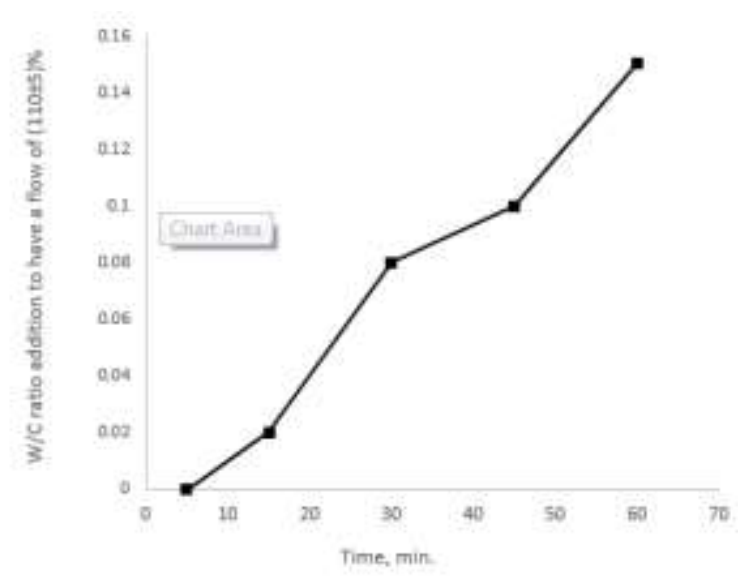

Figure 4: Effect of re-tempering beginning time of cement mortar at high temperature (mix 1:3, initial $\mathrm{w} / \mathrm{c}$ ratio $=0.6$, temperature $=40^{\circ} \mathrm{C}$ )

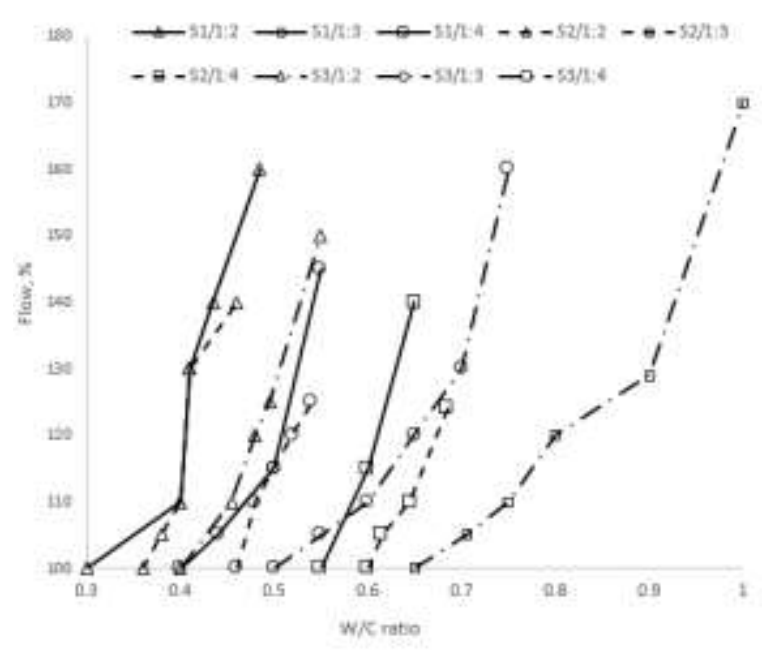

Figure 5: Effect of mix proportion on drying shrinkage of cement rendering, applied on clay bricks walls (using type S2 sand) 


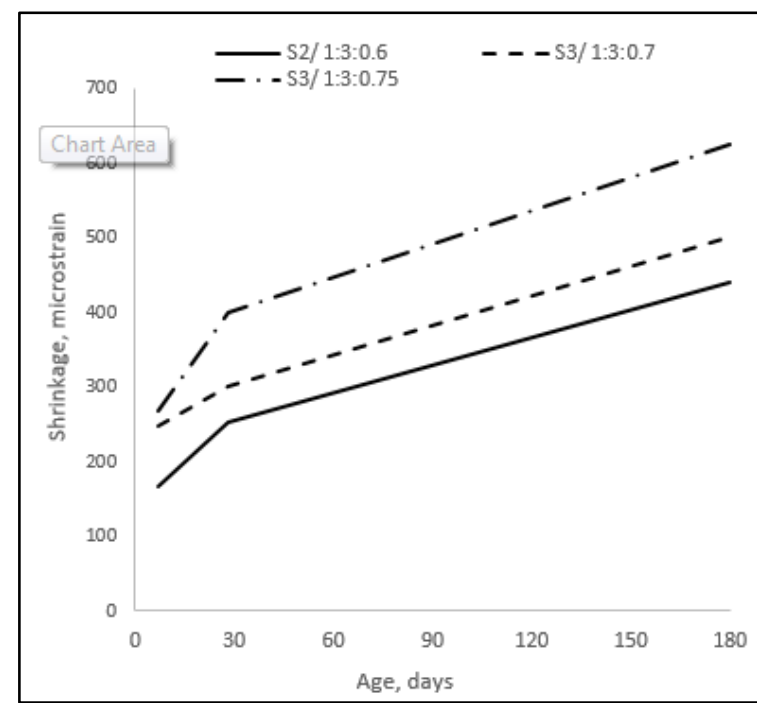

Figure 6: Effect of sand fineness on drying shrinkage of cement rendering

\section{Conclusions}

- The suitable flow of cement mortar for rendering should be $190 \pm 10 \%$ (as stated by rendering workers in the site), which means the water content should be higher than that required for standard flow of $110 \pm 5 \%$ by $10 \%$.

- The required workability of cement mortar changes with the used mix proportion. Where it increases with increase of water or cement content and decrease with increase of the fineness of sand used.

- The cement content in the mix has main role in determining the age that cracks occur. Generally, cracks were occurred in mixes 1:2 and $1: 3$ at one day and 7 days age respectively. While for mix 1:4 they appeared after six months.

- When increasing water content in the mix, the number of cracks increase, and appear in early age.

- The cracks on the block walls are more than those on brick walls.

- Continuing curing for 7 days (spray by water twice for seven days) has a noticeable effect on reduction cracks on the cement render.

\section{References}

[1] A.M. Neville, "Properties of concrete," $5^{\text {th }}$. Edition, 1307 pp, 2011.

[2] IQ.S. 5, "Portland cement," Iraqi specification, Central Agency for Standardization and Quality Control, 1984.

[3] IQ.S. 45, "Aggregate of Natural Resources Used in Concrete and Construction," Iraqi specification, Central Agency for Standardization and Quality Control, 1984.

[4] B.S. 882, "Specification for aggregates from natural sources for concrete," 1992.
[5] B.S. 1199, "Specifications for building sands from natural sources," 1976.

[6] ASTM C230-14, "Standard Specification for Flow Table for Use in Tests of Hydraulic Cement," 2014.

[7] ASTM C596 -09, "Standard Test Method for Drying Shrinkage of Mortar Containing Hydraulic Cement, 2018.

[8] "Quality assurance for cement plastering," http://www.rdso.indianrailways.gov.in/works/uploads/ File/Pamphlet $\% 20$ on\%20Quality\%20assurance $\% 20$ for $\% 20$ Cement $\% 20$ plastering(1).pdf

[9] ACI 224R-01, Control of cracking in concrete structures,"pp. 11-17, 2001. 